\title{
Totem e tabu: uma revisão
}

\author{
Totem and taboo: a review
}

\section{Luiz Roberto Monzani}

Docente do Programa de Pós-graduação em Filosofia da Universidade Estadual de Campinas (Unicamp), Campinas, SP - Brasil, e-mail: luiz.monzani@pq.cnpq.br

\section{Resumo}

Instrumentalizando o mito da horda primitiva apresentado por Freud em Totem e tabu, recebemos uma explicação do que seria a origem da civilização tal como a conhecemos a partir de um ato fundador. Este é um crime coletivo (concebido como ato real) do qual a civilização é fruto e do qual derivam todas suas características como neurose, incesto e agressividade, mas também seus contrários, de modo que é exposta a história do próprio psiquismo e de seu acesso à cultura. Com isso, Freud responde afirmativamente à simples pergunta: deve-se incluir o sujeito no processo coletivo? Assim, articula a psicologia individual e a psicologia coletiva, problematizando-as, sustentando o processo de trânsito da natureza à cultura, da individualidade natural à comunidade cultural, sendo que, em princípio, não haveria anterioridade de uma psicologia sobre a outra, senão simultaneidade. Por consequência, conclui-se que o problema, portanto, é invertido: não se trata da consciência moral levar à renúncia pulsional, mas, o contrário: a renúncia pulsional é que cria a consciência moral.

Palavras-chave: Freud. Psicanálise. Renúncia. Civilização. Cultura. 


\section{Abstract}

From the myth of the primal horde presented by Freud in Totem and taboo we received an explanation of what would be the origin of civilization as we know it, from a founding act, a collective crime (conceived as real act) which has the civilization as result, and which derives all its features such as neurosis, incest, aggression, and also the opposite ones, in order to expose the history of its own psyche and its access to culture. Thus Freud responds affirmatively to the simple question: should one be included in the collective process? Therefore he articulates the individual psychology and the collective psychology, questioning both, sustaining the process of transit from nature to culture, from natural individuality to the cultural community considering that, in principle, there would be no priority of one psychology over the other, but simultaneity. Consequently, it is concluded that the problem is, therefore, reversed: it is not about the moral conscience leading to the impulsive renunciation, but the opposite: the impulsive renunciation creates the moral conscience.

Keywords: Freud. Psychoanalysis. Renunciation. Civilization. Culture.

Um dia, os varões que não tinham fêmeas se rebelaram contra o tirano. A horda patriarcal se transformou em uma irmandade de filhos que mataram o pai, fizeram-no aos pedaços e o repartiram com as mulheres. A fim de conservar a nova ordem social e impedir que se formasse uma nova tirania, decide-se que ninguém podia ocupar o lugar do pai. Mas, evidentemente, os membros da comunidade, a irmandade, não podiam impedir uns aos outros de formar novas famílias com o chefe predominante. Em lugar da grande família com o pai tirânico, sucedem-se várias famílias cujos pais entendiam-se até certo ponto. Todos eles adoravam o totem em memória do arquipai.

Em primeiro lugar, é interessante notar que o nascimento do grupo é correlativo de um crime cometido em comum. Na origem, no big bang da civilização (ENRIQUEZ, 1983), houve, portanto, um crime cometido em conjunto: esse é o ato fundador, original. É, portanto, um ato real e não simplesmente sonhado.

Em segundo lugar, na verdade, por aceitar a divisão do social, é necessário que o pai se perceba como pai, isto é, que a civilização tenha 
aparecido e que as relações de parentesco sejam estabelecidas e reconhecidas. Isso é a consequência da reunião. Nos tempos primordiais não se conhecem senão relações de força.

Em terceiro lugar, a invenção da primeira relação de solidariedade acontece quando, reconhecendo o outro como outro, podem viver como irmãos.

Em quarto lugar, eles expressam a solidariedade e reconhecem o liame libidinal que os une no ódio comum contra o pai. E eis o golpe de gênio de Freud: se é o ódio que transforma os seres submetidos em irmãos, é seu assassinato que constitui o chefe da horda em pai. Em outros termos, o pai não existe senão como ser mítico. O pai é sempre um pai de morte.

Ora, pois, qual é a definição de grupo? Um grupo é uma coleção de indivíduos que introduziu uma pessoa em seu super-ego e, sobre a base desse fator comum, identificou-se com os outros em seu ego. Isso, naturalmente, somente faz referência a grupos que têm um chefe. Só que o momento coextensivo existe a partir de um projeto comum - momento que, nas origens, é o de festim. É isso que permite o nascimento do irmão.

Para ele, portanto, o Complexo de Édipo exige que se excluam certas atitudes, senão o "poder frenético do amor" (BALINT, 1971, p. 182) inclui a ausência de sociedade. É por isso que a sociedade aplica normas preventivas, mas que advêm da própria sexualidade, a qual não pode existir em estado selvagem. Enfim, sem as limitações sexuais (impostas pelos próprios indivíduos), não existiria civilização (BALINT, 1971).

Agora, quanto mais primitivas as sociedades, mais clara fica sua dependência do objeto instintivo (não nos esqueçamos que nos primórdios da civilização não existia sociedade). Enfim, por mais que rodeemos, há sempre um ponto cardeal de toda a civilização: o Complexo de Édipo. E, também, de cada indivíduo particular. Toda a estrutura da sociedade depende desse fator.

Nesse sentido, podemos dizer que a estrutura social é fruto, é resultado de um ataque levado a cabo por indivíduos sexualmente excitados.

De qualquer maneira, fica claro que todo processo civilizatório é, por essência, conflitual e de vocação neurótica. Os irmãos sentem-se 
culpabilizados (pela ambivalência do sentimento) e, ao mesmo tempo, ele, o poder, se torna sagrado. É por isso que sempre há uma possibilidade, uma plausibilidade do crime.

Nós compreendemos agora porque o parricídio é indispensável à criação da cultura: ele nos introduz no mundo da culpabilização, da renúncia. Nós passamos de um estado de forças a um mundo de relacionamento de alianças e de solidariedade (sociedade de direito).

De qualquer maneira, há indícios suficientemente claros que o "desejo do incesto" está presente em todas as sociedades - particularmente nas sociedades primitivas que tinham uma verdadeira obsessão contra o incesto.

Dentro da lei exogâmica, o elemento perceptível da proibição do incesto é o elemento fundador da família e, portanto, das estruturas do próprio indivíduo. É por isso que a proibição representa uma verdadeira passagem entre a natureza e a cultura. É por isso, ainda, que a civilização nasce do recalque e é por isso também que a questão de Édipo deve ser tratada em termos psicológicos individuais e é decisiva para o advento da cultura. Enfim, ou há o caos (a realização da pulsão por via imediata) ou há o socius, que é incompatível com a satisfação imediata.

É por isso que, também, se as primeiras instituições promulgam tantas interdições, isto é verossímil: eles tinham muito mais medo do incesto do que nossa sociedade, isso porque a primeira instituição social fez nossa sociedade recalcar o que estava à flor da pele. Assim, organizou-se e canalizou-se a rivalidade. O que, mais uma vez, confirma que a obra civilizadora é neurótica em sua própria essência.

É por isso que só uma teoria do tipo levy-straussiana (refiro-me a Structures élémentaires de la parenté, 1967) teve sucesso. Na base, na fronteira entre natureza e cultura está Édipo. É por isso também que todas as teorias sociológicas que tentam explicar um fato social por outro fato social estão fadadas ao fracasso. Esse é o caso, por exemplo, pese sua imensa cultura psicanalítica, de Roger Bastide (1948), em Sociologia e psicanálise, obra na qual, entre outras afirmações, encontramos que, "do ponto de vista sociológico" - único adotado nesse livro (sendo que um pouco mais adiante o social não poderá explicar o social). 
De qualquer maneira, retomando o fio proposto, o que Freud inova desde Durkheim é a instância interditora para visar à pulsão sexual no imediato e permitir uma lei no indivíduo. Desse modo, a "questão de Édipo" não é posta no desenvolvimento do indivíduo (só), mas ela é a questão decisiva pela qual deve responder todo o "corpo social" para advir ao estado de civilização, isto é, para viver nas condições de estabilidade e simbolizadas. O desejo mesmo não pode se entender senão na medida em que ele corresponde a uma lei de organização. Mas o sonho da endogamia não deixa de ser fascinante e isso por meio de um duplo movimento: amor e ódio (ambivalência) - o super ego (consciência moral). Não somente o crime é fundador; ele também rodeia a todo instante.

Assim, a interdição do incesto, no seu caráter imperativo, é a condição de possibilidade da passagem da natureza à cultura. Na verdade, existem duas condições de possibilidade:

1) a troca social;

2) o sonho da endogamia (a concentração de pequenos grupos).

Freud teve sucesso em explicar não por que a origem do incesto é conscientemente condenada, mas como ele é inconscientemente desejado. Dito e redito, Totem e tabu é percebido como hipótese de proibição do incesto e de suas origens. Mas, como todo mito, aquele de Totem e tabu se apresenta com uma grande força dramática, e comporta duas interpretações:

a) o desejo da mãe ou da irmã, a morte do pai e o arrependimento dos filhos não correspondem sem dúvida a nenhum fato;

b) e traduzem-se, pode-se dizer, sob uma forma simbólica ao mesmo tempo durável e antiga.

O prestígio desse sonho, com seu poder de modelar os pensamentos dos homens, provém precisamente do fato de os atos por ele evocados não serem jamais cometidos porque a cultura está sempre aí para se opor. As satisfações simbólicas não constituem outra coisa que 
o fato de serem expressão da desordem, ou melhor, da contraordem. “Encarada sob esse ângulo a formação dos mitos e dos contos deveria muito mais ser considerada como um desenvolvimento cultural negativo e, numa certa medida, como depósito para as moções libidinais" (LÉVI-STRAUSS, 1967, p. 563).

Mas, exatamente porque tem a função de depósito, em certo sentido, a formação oculta a diferença ou a separação interior, isto é, a história do próprio psiquismo e de seu acesso à cultura. Em outros termos, fracassa em introduzir a gênese em seus próprios conteúdos.

Desde o ponto de vista genético, duas organizações sucessivas ou distintas que se correspondem podem atualizar-se em um sujeito, como se tivera validez simultânea. Enfim, descriminar o fora (no sentido de realidade, do mundo exterior) implica necessariamente separar aqui, de dentro, o processo que ficou incorporado no seu acesso à cultura; é exatamente o trânsito da natureza à cultura, da individualidade natural à comunidade cultural.

Mas essa individualidade existe na lembrança do pai ameaçador, na recordação do pai castrador da horda primitiva. E o super-ego regulador sobre um fundo de individualidade do pai-morto vai se determinando como a não satisfação dos impulsos libidinais na cultura. A cultura é, de uma certa maneira, o velar do assassinato do pai. É exatamente isso o que contém o adulto.

Todas aquelas manifestações desta origem, que logo encontramos na sociedade, assim o companheirismo, o espírito de corpo, etc., derivam incontestavelmente da inveja primitiva. Ninguém deve querer se sobressair; todos devem ser e obter o mesmo. A justiça social significa nós nos recusarmos muitas coisas para que os demais tenham que renunciar a elas (o que é o mesmo, na raiz da consciência social e do sentimento de dever) (FREUD, 1976, p. 144).

Desse modo, a justiça social implica delinear a satisfação das necessidades, mas fora do sinal da aparição do desejo; isso quer dizer que o indivíduo passa a ser foco de uma existência virtual do passado no presente. 
Como desde o indivíduo se dá essa ampliação coletiva? O laço que os reúne é o seguinte: tem que haver algo em comum que os ligue. Ora, o comum é sempre o desejado. Logo, parte-se do desejo para a amplificação até o social. Não é, portanto, o "instinto gregário", mas o interesse que está em jogo.

É contra o instinto gregário essa "naturalização social" a que se dirigem as análises posteriores de Freud: mostrar a aparição do social ao nível de uma crescente universalidade (a qual tem a infância como primordial), ou melhor, do desejo insatisfeito originário (aqui, ter a mãe só para mim) e a interdição paternal, como figura do Outro. Ou, melhor dizendo: o temor de perder o objeto amado e os ciúmes que evoca aquele Outro dá lugar à angústia como única forma de dar resposta no nível da criança. Por viver esse drama, seu único consolo é que todos os irmãos são tratados por igual.

Todas aquelas manifestações dessa ordem, que logo encontramos em sociedade, assim como o companheirismo, o espírito de corpo, derivam, incontestavelmente, da inveja primitiva. Ninguém deve querer se sobressair, todos devem querer o mesmo. A justiça social significa que nós recusamos a nós mesmos muitas coisas desde que eles também devam renunciar a elas. Essa reivindicação de igualdade é a raiz da consciência social e do sentimento de dever.

Assim, pois, o sentimento social repousa na transformação de um sentimento primitivamente hostil no enlace positivo que teme a natureza de uma identificação (desse ponto de vista, a justiça social implica satisfação fora do desejo).

É exatamente assim, nesse processo de transformação, que se efetua, sob a influência do enlace em comum, a base da ternura, a pessoa exterior à massa. É por isso que o homem é um animal de ordem doméstica, porque sempre o complexo de Édipo está à espreita para furar, para impor aí seus direitos. De qualquer maneira, sempre está presente (virtual ou atualmente) o passado no presente.

Vejam bem, não se trata de Freud, como psicólogo, tender a fazer mal o que a Sociologia faz bem. Não se trata de tentar uma "psicologia aplicada" e invadir inadequadamente o campo da Sociologia. O que Freud faz 
é responder à simples pergunta: deve-se incluir o sujeito no processo coletivo? A que ele responde que sim. Daí o recurso ao passado no subjetivo.

Quer dizer, Freud quer compreender os pressupostos básicos que estão no começo da história. Para isso, trata de recriar as condições sem as quais esse trânsito da natureza à cultura não poderia ter sido levado em conta. Freud simplesmente abarca uma ciência verdadeiramente humana ao incluir o respeito no processo coletivo.

Freud está não só dizendo que os albores levam a natureza à cultura, mas, em todos os tempos, inclusive no presente, essa passagem é feita, só que de maneira oculta. O poder coletivo é exatamente isto: transformar da natureza própria como exterior. Trata-se de recriar a ciência nas condições básicas que estão no começo da história. Portanto, é como se recriasse as condições sem as quais esse trânsito da natureza à cultura não seria efetivado: o poder. É esse passo significativo que propicia a formação de um novo poder coletivo de produzir a história. Trata-se de um exterior como natureza própria.

O dilema para o homem cultural seria este: assim como o filho nasce de dois indivíduos (individual), o real coletivo histórico nasce de um fator coletivo (horda primitiva) e tem esse ocultamento na origem histórica.

Aqui, a forma do Outro aparece como modelo (sintético) de minha relação social porque o presente o contém como aquilo do qual seu sentido deriva (atual). Eis aqui a gênese da religião e da moral. Haveria, assim:

1) por um lado, no pai, somente uma psicologia individual;

2) por outro lado, na horda, só psicologia coletiva.

É exatamente este o nó a desatar: a psicologia individual e a psicologia coletiva.

Condições de representação (e não condições de representabilidade), portanto, correspondem a uma questão transcendental e alheia ao freudismo. É nesse sentido que a natureza, tanto própria como exterior, fornece as condições de representatividade. 
É como se Freud quisesse traçar as coordenadas mínimas temporais no espaço, sem as quais o homem não pode se incluir na história para encontrar nela a estrutura histórica da subjetividade; sem as quais o homem não pode incluir-se como ciência humana. Enfim, discriminar por fora (no sentido da realidade) do mundo exterior implica necessariamente separar desde dentro o processo que ficou incorporado no Eu com acesso à cultura: é o trânsito; o processo de trânsito da natureza à cultura, da individualidade natural à comunidade cultural.

Esse processo é, portanto, o processo de trânsito da natureza para a cultura, que persiste ameaçante; lembra-nos do pai castrador da horda primitiva. A todo instante, vamos dizer assim se se quer esquecer o que é lembrado.

Freud parte, portanto, do homem primitivo de onde a unidade combinatória era a infância natural. Na realidade, parte da família natural para o alicerce paterno. O pensador passa, então, para a seguinte questão: como entender esse "ao mesmo tempo" no que concerne ao individual e ao social?

A massa nos mostra, pois, com a ressurreição da horda primitiva. Assim como o homem primitivo sobrevive virtualmente em cada indivíduo, também na massa humana pode-se reconstruir a horda primitiva. Deduziremos, pois, que a psicologia coletiva é a psicologia humana mais antiga (FREUD, 1976, p. 117).

Enfim, Freud recria o passado no presente. Na Origem não há um ponto de partida, um instante em que a cultura deve vir da natureza. Nesse sentido, e só nesse sentido, há uma nova estruturação e uma nova forma de relação.

Assim, segundo Freud, há uma psicologia do pai como indivíduo natural e a prole. Ou, melhor dizendo, havia uma psicologia natural (individual), mas sem gênese. Esse ponto será explicado posteriormente.

Permitam-me citar um texto de Freud:

o pai primordial da horda não era imortal (como passou a ser mais tarde por divinização). Quando morria devia ser substituído. O substitui, provavelmente, um filho mais jovem que até então havia sido 
indivíduo-massa como os demais - portanto, deve existir alguma possibilidade de transformar a psicologia das massas em psicologia individual. Deve aliar uma condição sob a qual essa transformação consuma-se facilmente como às abelhas lhes é possível, em caso de necessidade, fazer de uma larva uma rainha... Somente podemos concebê-la assim: o pai primevo havia impedido a seus filhos a satisfação de suas aspirações sexuais diretas. Os compelia à completa abstinência e, por conseguinte, os impedia de estabelecer entre eles ligações afetivas que podiam brotar das aspirações de meta sexual inibida. Os compeliu, por assim dizer, à psicologia das massas (FREUD, 1976, p. 118).

Assim, o problema da transformação da psicologia coletiva em psicologia individual se produz logo que o pai é assassinado. Diz Freud (1976, p. 117): “Assim como o homem primitivo sobrevive virtualmente em cada indivíduo também toda a massa humana pode reconstituir-se na horda primitiva".

Em outro momento, Freud (1976, p. 117) afirma: "A massa se mostra, pois, como uma ressurreição da horda primitiva, assim como o homem primitivo sobrevive virtualmente em cada indivíduo". Nesse sentido, a psicologia coletiva esteve nos albores da humanidade.

Da psicologia coletiva à psicologia individual - o festim.

Em contrapartida, Freud coloca que:

a primeira reflexão que surge diante do nosso espírito nos mostra em que ponto temos de retificar nossas anteriores afirmações. A psicologia individual tem, com efeito, que ser tão antiga como a psicologia coletiva. Pois, desde o princípio, teve de haver duas psicologias: a dos indivíduos (que compõem a massa) e a do pai ou chefe (FREUD, 1976, p. 144).

Assim, em princípio, não haveria anterioridade de uma psicologia sobre a outra, senão simultaneidade. Mas ambas estão ainda sob o domínio do natural. Esse indivíduo (o qual denomina super-homem) era narcisista cultural e, portanto, não tinha super-ego. E aqui surge a metáfora das abelhas. O problema, pois, foi resolvido com o assassinato do pai. Por sua morte surge o primeiro indivíduo cultural: passou-se da horda à aliança. 
Precisamente aqui vemos outro campo, qualitativamente novo. Há abertura de outro campo porque há trânsito do instante da satisfação ao outro, o qual permanecia o proto-padre (sensível, sem racionalidade), ao campo infinitamente aberto e simbólico, separado do sensível, pelo assassinato cuja memória se reprimiu. Ele era todo finito para os filhos e sua morte abre a interiorização psíquica. Por sua morte, produz-se o advento da cultura, do primeiro indivíduo cultural. É assim que Freud explica o advir do indivíduo social.

Em certo sentido, ocultar a diferença ou a separação interior, isto é, a história do psiquismo de seu próprio acesso individual à cultura, não é outra coisa senão introduzir a gênese em seus próprios conteúdos. Desde o ponto de vista genético, duas organizações sucessivas ou distantes se correspondem ao enlace, e soluções contraditórias podem atualizar-se em um sujeito como se tivera validez simultânea.

Freud parte do homem primitivo de quem a unidade comunitária era a família natural. Na realidade, parte dessa família natural para a aliança paterna. O homem filogeneticamente mais antigo é o único que existe na infância, que subsiste e que deve ser substituído pelo modo cultural de origem mais recente.

Para Freud, a contradição entre natureza e cultura aparece como dois polos:

a) campo mínimo: homem, mulher, filhos;

b) campo máximo: sociedade global.

O problema, portanto, é invertido: não se trata da consciência moral levar à renúncia pulsional, mas, o contrário: a renúncia pulsional é que cria a consciência moral. Isso porque, nas origens, o Eu é um Eu assassino, e, portanto, o sentimento de culpa esteve presente desde as origens.

No trânsito realmente efetuado, há a origem da história do homem, da horda primitiva, da aliança fraterna: o Édipo individual carece de sentido nas condutas do homem, caso se separe do Édipo primevo. Somente se incluirmos no trânsito da cultura individual a cultura da horda primitiva, a verdade do drama individual se aclara: 
E opino que logo chegará o tempo em que se poderá ampliar uma tese que nós psicanalistas formulamos há muito tempo, agregando ao conteúdo válido para o indivíduo, entendido ontogeneticamente, o complemento antropológico de concepção filogenética (FREUD, 1986, p. 76, tradução nossa).

Qual é, portanto, a origem do sentimento de culpabilidade?

À cette question, Freud répond: 1'ambivalence affective et le complexe d'Oedipe. Ces deux concepts sont d'ailleurs essentiels dans la demarche qui lui permet d'articuler ontogenèse et phylogenèse. Après avoir découvert la fonction fondatrice et structurante du complexe d'Oedipe dans la psyché de tout sujet humain, Freud éprouve la necessite de lui attribuer une place originaire dans l'histoire de l'humanité en general. L'origine phylogénétique du sentiment de culpabilité [consciência moral] en l'homme vient du meurtre réel du père primitif par les frères qui éprouvaient à l'égard de ce pére des sentiments ambivalents. Suivons Freud dans son récit explicatif (CHARRON, 1979, p. 104). ${ }^{1}$

Agora precisaríamos discorrer mais detidamente sobre a diferença entre história evolutiva e a filogenética na obra de Freud. Porém, esse é um ponto que necessita de outro artigo para ser esclarecido e exposto. Assim sendo, ficará para outra vez!

\section{Referências}

BALINT, M. Sexualidad y sociedad. In: ADORNO, T. W. et al. Freud en la actualidad. Barcelona: Barral, 1971. p. 173-202.

\footnotetext{
1 Permitam-me aqui um breve parêntese, acerca do conceito de evolução. 0 conceito de evolução de Darwin diferia do de Lamarck em dois pontos essenciais pouco lembrados hoje, os papéis da "vontade" ou "volição" e de uma força ortogenética interna. Na ausência do mecanismo de seleção natural, Lamarck introduziu o que Darwin chamou de "contra-senso de Lamarck, a lenta vontade de adaptação" (RITV0, 1992, p. 250). Darwin nunca aceitou como explicações válidas o "progressivo desenvolvimento" ou "adaptações a partir da lenta disposição dos animais" ou, quanto a isso, a "geração espontânea". Mas, quanto aos outros meios de modificação que atribuiu a Lamarck, inclusive "uso e desuso", Darwin encontrou para eles lugar em sua própria obra, que os disseminou de modo mais efetivo que a de Lamarck (RITV0, 1992, p. 54). Havia uma confusão entre darwinismo e lamarckismo que só mais tarde, nos anos 30/40/50, e principalmente com a descoberta do DNA, passaram a não ser mais confundidos; enfim, o zeigeist da época era propício à confusão.
} 
BASTIDE, R. Sociologia e psicanálise. São Paulo: Instituto Progresso Editorial, 1948.

CHARRON, G. Freud et le problème de la culpabilité. Ottawa: Éditions de l'Université d'Ottawa, 1979.

ENRIQUEZ, E. De la horde à l'État. Paris: Gallimard, 1983.

FREUD, S. Obras completas. Rio de Janeiro: Imago, 1976.

FREUD, S. Obras completas. Buenos Aires: Amorrortu, 1986.

LÉVI-STRAUSS, C. Les structures élémentaires de la parenté. Paris: Mouton, 1967.

RITVO, L. B. A influência de Darwin sobre Freud. Rio de Janeiro: Imago, 1992.

Recebido: 29/04/2011

Received: 04/29/2011

Aprovado: 21/06/2011

Approved: 06/21/2011 